\title{
REVIEW
}

\section{CONTRIBUTIONS OF THE NATIONAL SCIENCE FOUNDATION TO AGRICULTURAL RESERCH IN SRI LANKA}

\author{
R. SENARATNE ${ }^{1 *}$ and SEETHA I WICKREMASIGHE ${ }^{2}$ \\ ${ }^{1}$ Faculty of Agriculture, University of Ruhuna, Mapalana, Kamburupitiya. \\ - National Science Foundation, 47/5, Maitland Place, Colombo 07
}

(Received: 06 August 1999 ; accepted: 11 February 2000)

Summary: Agricultural Science is one of the fifteen fields receiving support for research by the National Science Foundation (NSF). Since the inception of the research grant scheme in 1970 by the then National Science Council (NSC) and its successors the Natural Resources, Energy and Science Authority (NARESA) and the National Science Foundation (NSF**), a total of 115 grants in the field of agricultural science have been awarded at a cost of Rs. 15.9 million in local funds up to 1997. Of the grants awarded in agriculture-related fields, the highest funding has been on fruit crops $(26.5 \%)$ fullowed by cereals $(19.9 \%)$, plantation crops $(13.1 \%)$, vegetable crops $(5.50 \%)$, grain legumes $(4.4 \%)$, tuber crops $(4.0 \%)$ and export agricultural crops $(2.6 \%)$. Other categories of crops received less than $2 \%$ funding. In terms of disciplines, Post-harvest Technology, Biotechnology, Genetics \& Plant Breeding, Soil Science, Agricultural Engineering \& Machinery and Agronomy have received relatively high funding and have respectively accounted for $30.6,16.4,16.1$, $9.0,6.3$ and $4.6 \%$ of funds. Of the 115 grants funded, only $8(6.9 \%)$ were related to animal science.

In terms of institutions, the Faculties of Agriculture in the Universities have received ahout $75 \%$ of funding while the National Agricultural Researcl. System (NARS) has received about 25\%. Since the Faculties of Agriculture receive only a nominal sum for rese arch through their regular budgetary allocation, the NSF has been a very important suurce of funding for research in the faculties of Agriculture in the country, which have ahout 250 staff members or about $40 \%$ of the agricultural scientists in the country. The NSF has been the principal source of funding for agriculicural research in the country until the estahlishment of the Council for Agricultural Research Policy (CARP) in 1987. As opposed to the NSF, the CARP funding has been mainly (i.e. $>80 \%$ ) to the NARS.

The research grant scheme of the NSF and the activities connected thereto have contributed substantially to the promotion of scientific and intellectual activities among agricultural scientists, advancement and dissemination of knowledge, development of human resources/postgraduate training, establishment of professional contacts and reinforcement of research capabilities and laboratory facilities of institutions. Thus the NSF has made a singular contribution not only in supporting and advancing agricultural research in the country, but also in strengthening research capabilities and laboratory facilities of the NARS

" Corresponding author: a meraber of the NSF working committee on Agricultural Science \& Forestry

- In all future references to "NSF" no distinction is made between NSF and its predecessors, NARESA \& NSC 
and the Faculties of Agriculture. With the advent of globalization, the agriculture sector will face formidahle challenges and threats. Hence, the NSF research grant scheme will become still more relevant and important in the future. Therefore the NSF may augment its research funding for hasic, applied and aclaptive research related to agricultural issues in order to meet challenges in the agriculture sector of the country in the twenty first century.

Key words: Agricultural Sciencies, Council for Agricultura! Resercls Policy, National Science Foundation, Research grants

\section{INTRODUCTION}

Sri Lanka covers an area of 65,611 square kilometers ( 6.5 million ha) of which about 22,400 square kilometers ( 2.3 million ha) are agricultural lands. Agriculture is still the mainstay of the economy as well as the main source of employment in Sri Lanka. But, the contribution of the agriculture sector to GDP has gradually declined from $38 \%$ in 1960 to $28 \%$ in 1984 and to $18.8 \%$ in 1997, showing the diversification of the economy. Similarly the employment in agriculture which accounted for $53 \%$ in 1960 , declined to $45 \%$ in 1980 and to about $38 \%$ in $1997 .{ }^{\prime}$

During the past 30 years or so, the domestic agriculture sector has grown faster than the plantation sector. The paddy sector has grown by 2.3 per cent per. annum achieving near self-sufficiency. The subsidiary food crops and minor export crops sub-sectors have grown by 4.4 per cent. During this period, the tea sector has grown by 1.3 per cent per annum, rubber output declined by 0.6 per cent per annum and coconut increased by 1.6 per cent per annum. ${ }^{1}$ However, about 75 per cent of the Sri Lankan population still live in rural areas. Therefore improvement of productivity in the agriculture sector is vital to achieving faster economic growth and raising the living standards of the rural folk in the country.

\section{Agricultural research in Sri Lanka}

Agricultural research in Sri Lanka is carried out by 22 institutions and departments coming under eight Ministries" (Table 1). Thus the institutions carrying out agricultural research in Sri Lanka are 'scattered' over many Ministries, rendering co-ordination difficult. As a result, the research activities in the country have been conducted in a very uncoordinated manner resulting in fragmented research with inadequate linkages within the Ministries and between the Ministries and the research institutions. A major constraint in the agriculture research system has been the absence of a mechanism for coordinating and consolidating research efforts, identifying national research needs and establishing priorities consistent with the needs. Besides, until recently, research information has not been collected, analyzed and interpreted in a manner that enables it to reach the levels where decisions are made on priorities and appropriation of funds. ${ }^{4}$ These issues are now being addressed by the Council 
for Agricultural Research Policy (CARP) since its establishment in 1987. However, the agricultural researches conducted in the University system are still mainly individual-driven with little or hardly any focus on national priorities.

Table 1: Ministries and Departments/ Institutions undertaking research in Agricultural Science (Gunasena and Marambe, 1998, adapted from Senanayake,1990)

Ministries

Agriculture and Lands

Plantation Industries

Livestock Development and Estate Infrastiucture

Environment and Forestry

Fisheries and Aquatic Resources Development

Irrigation, Power and Energy

Science and Technology

Education and Higher Education

\section{Departments/Institutions}

Department of Agriculture, Department of Export Agriculture, Hector Kobbekaduwa

Agrarian Research \& Training Institute

Tea, Rubber; Coconut and Sugar' cane Research Institutes, Department of Wildlife Conservation

Department of Animal Production \& Healtl, Veterinary Research Institute

Forest Department.

National Aquatic Resources Reserarch and Development Agency (NARA)

Irrigation Department

Industrial Technology Institute (former CISIR)

Faculties of Agriculture at Peradeniya, Ruliuna, Eastern, Jaffna,Wayamba and Rahangala Faculty of Veterinary Medicine \& Animal Science, Postgraduate Institute of Agriculture

Besides, the interaction between the Secretaries to the Ministries and the Directors of research institutions or departments is still mainly concerned with financial and administrative matters and little time is spent on review of research programmes and priorities. Poor research infrastructure and inadequacy of operating funds are also major constraints for research. 
Until recently, research progxammes have been concentrated mainly on rice, tea, rubber and coconut. Research effort on rice has produced tangible results, achieving near self-sufficiency. There have been many noteworthy achievements in research on major agricultural crops, which have been reviewed in detail. ${ }^{5-7}$ During the last decade or so, the yields of the major agricultural crops have not, been increasing and the productivity has been stagnant.

\section{Contribution of NSF in supporting agricultural research in Sri Lanka}

Before the establishment of the National Science Council (NSC) in 1968, there was no institution in the country that provided funds for agricultural research. Thus the staff in the agricultural institutions had to totally depend on the funds received from the Treasury for agricultural research. The staff of the Faculty of Agriculture, University of Peradeniya, the only Faculty of Agriculture that existed in the country until 1978, had no source of funding for research. As a result, their research activities had been seriously constrained.

In such circumstances, the establishment of the NSC in 1968, inter clic, to provide funds for research has administered a fillip to conducting agricultural research in the country. Information on the number of applications received, the number and value of grants awarded in the field of agricuiture and animal husbandry by the NSF during the period of 1982 to 1999 is given in Table 2. This field has accounted for $17 \%$ of the total applications received and $10 \%$ of the total funds disbursed for research by the NSF during the above period. Due to poor quality of the research proposals received, no research grants were awarded in 1993 and 1994. Recognizing this issue, the then Steering Committee on Agriculture and Animal husbandry organized a series of seminars for the young scientists and researchers on "Preparation of project proposals and final reports." The highest number of applications (i.e. 26) has been received in 1988 after which it has shown a declining trend, and in 1999, this has reduced to three. This has been in spite of the fact that the strength of research officers and scientists in agriculturerelated fields in the country has increased since 1987. With the advent of the research grant scheme of CARP following its establishment in 1987, agricultural scientists have submitted a large number of research proposals to CARP which exclusively funds agricultural-research that fall in line with national priorities. This has resulted in a low number of applications being received by the NSF after 1987.

A sharp increase in the value of grants awarded is evident from 1995 onwards which has been as a result of the NSF receiving more funds for research from the Treasury. For instance, the NSF received a sum of Rs. 4.9 million for research in 1994 which was increased to 21.8 million in 1995 and to Rs. 32.0 million in 1999. Out of 248 proposals received in the field of agriculture and anima] husbandry from 1982 to 1999 only 67 proposals, ajoui 27 per cent of the proposals 


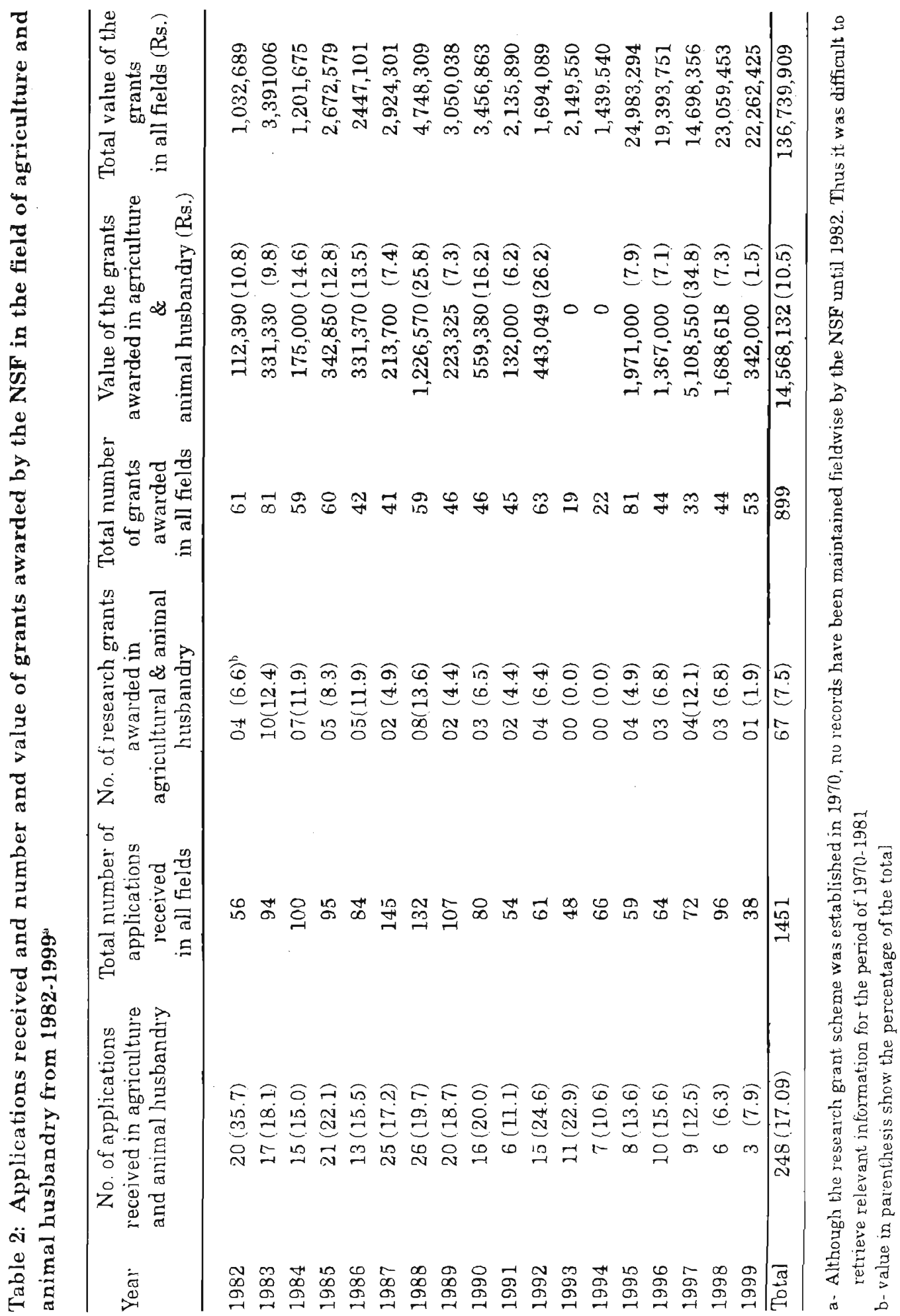


submitted, have been funded. Poor formulation of research proposals, lack of scientific merit, lack of relevance to national priorities, non-submission of revised proposals taking into account the referees' comments etc. have been the major causes for rejection of research proposals. Since the inception of the research grant scheme in 1970, the NSF has awarded a total of 115 research grants in the field of Agriculture up to 1997, amounting to a total sum of Rs. 15,981,471 (Table 3).

\section{(a) Commodity-wise funding}

Breakdowri of the NSF-funded research on major categories of crops and livestock during the period of 1970-1997 is given in Table 3. As evident therefrom, major funding in terms of the number of grants has been on cereals (18), legumes (15), plantation crops (11), export agricultural crops (8), vegetables crops (7) and fruit crops (6). They accounted for 15.7, 13.0, 9.6, 7.0,6.1 and 5.2 per cent of the total number of grants awarded, respectively. Of the 18 grants on cereals, 16 have been on rice, thus only two grants have been awarded on other cereals. Thus as a single crop, rice has received the highest number of grants accounting for 13.9 per cent of the total grants awarded by the NSF up to 1997. The number of grants on other individual crops has been few.

As regards the amount of funds provided, the highest was for fruit crops $(26.5 \%)$ followed by cereals (19.9\%), plantation crops (13.1\%), vegetable crops (5.5\%), grain legumes $(4.4 \%)$, tuber crops $(4.0 \%)$, export agricultural crops $(2.6 \%)$, medicinal plants $(1.3 \%)$ and sugarcane $(0.2 \%)$.

With regard to crops such as tea, rubber, coconut, sugar cane and cashew, there are separate research institutes mandated to carrying out relevant research on their production, processing and marketing aspects. Funds for these purposes are provided by the respective institutes, though it may not be adequate. However, when other agricultural crops are concerned, they mainly come under the Department of Agriculture and Department of Export Agriculture where each department has a large number of mandatory crops with the former dealing with over 60. In such situations, these departments may not be able to provide funds for necessary research even on some high priority crops. For example, though it is claimed that Sri Lanka is almost self-sufficient in rice, it has a huge cereal deficit and imports wheat and maize at a cost of about Rs.10 billion annually, which currently accounts for about $20 \%$ of the total cost of fnod imports. But as indicated above, of the 18 grants awarded by the NSF on cereals during the period of $1970-1997,16$ have been on rice. Thus there has been hardly any research funding on other cereals such as maize, finger millet etc., which prove very important in import substitution, saving foreign exchange and ensuring food security. Of the 115 grants awarded only $8(7 \%)$ have been on livestock (Table 3). Given the economic, social and nutritional importance of the livestock sector, the number of research grants in this sector has been disturbingly low. 
Table 3: NSF research grants categorised into commodities during the period of 1970-1997

Commodity

Grants áwarded:

(No)

$(\%)$

Crops

Plantation crops

Cereals

Paddy

Other cereals

Tuber crops

Grain legumes

Vegetable crops

Export agricultural crops

Sugar cane

Medicinal plants

Fruit crops

Livestock

Dairy

Rabbit

Pigs

Buffalo

Fish

Other

Non-commodity

Total
11

18

16

2

3

$15 \quad 13.0$

7

8.

4

1

6

1

1

2

1

1

2

34
9.6

15.7

13.9

1.7

2.6

6.1

7.0

3.5

0.9

5.2

0.9

0.9

1.7

0.9

0.9

1.7

29.6
Value of grants awarded

(Rs.)

$(\%)$
13. 1.

19.9

18.7

1.2

4.0

4.4

5.5

2.6

0.2

1.3

202,000

26.5

$4,238,279$

0.1

$$
9,940
$$

0.7

113,000

1.8

286,700

0.9

143,700

0.8

127,000

0.7

109,273

17.6

(b) Discipline-wise funding

Breakdown of the NSF- funded research grants awarded during the period of 1970-1997 in terms of major disciplines, is given in Table 4. Both in terms of the number of grants awarded as well as the level of funding, the highest was in agronomy which accounted for $27 \%$ of the grants awarded. Genetics \& plant breeding, post-harvest technology, entomology, pathology, agricultural engineering and soil science have been the other major disciplines that received relatively high funding. 
Table 4: NSF research grants categorised into disciplines during the period of 1970-1997

\begin{tabular}{lrrrr}
\hline Discipline & \multicolumn{2}{c}{ Grants awarded } & \multicolumn{2}{c}{ Value of grants awarded } \\
& $($ No. $)$ & $(\%)$ & $($ Rs. $)$ & $(\%)$ \\
\hline Agronomy & 31 & 27.0 & 729,325 & 4.6 \\
Genetics \& Breeding & 13 & 11.3 & $2,577,550$ & 16.1 \\
Entomology & 7 & 6.1 & 579,535 & 3.6 \\
Pathology & 7 & 6.1 & 328,996 & 2.1 \\
Post harvest technology & 10 & 8.7 & $4,889,420$ & 30.6 \\
Extension \& marketing & 2 & 1.7 & 35,200 & 0.2 \\
Agricultural Engineering & 7 & 6.1 & $1,003,652$ & 6.3 \\
\& machinery & & & & \\
Soil Science & 6 & 5.2 & $1,431,384$ & 9.0 \\
Biotechnology & 3 & 2.6 & $2,622,912$ & 16.4 \\
animal Science & 8 & 7.0 & $1,101,315$ & 6.9 \\
Other & 21 & 18.3 & 682,181 & 4.3 \\
\hline Total & 115 & 100.0 & $15,981,471$ & 100.0 \\
\hline
\end{tabular}

\section{Recipient institutions of NSF-funded research grants}

The number and value of research grants awarded by the NSF to the Universities and National Agricultural Research System (NARS) from 1970-1997 in agriculture-related fields are given in Table 5. Of the total of 115 grants awarded, the Universities-mainly Faculties of Agriculture, have received 85 (73.3\%) while other institutes/NARS have received only 31 grants $(26.7 \%)$. Thus the Universities have received about $75 \%$ of the total funds disbursed while the NARS receiving around $25 \%$.

The total strength of the academic staff in Faculties of Agriculture in the University System, including the Postgraduate Institute of Agxiculture is about 250, of which 123 have $\mathrm{Ph} \mathrm{Ds}$ and 53 have Master's degrees. ${ }^{2}$ On the other hand, the NARS has a total of $116 \mathrm{Ph} \mathrm{D}$ degree holders and about 180 Master's degree holders. Therefore the Faculties of Agriculture in the University system constitute a vast trained human resource base in the agriculture sector of Sri Lanka. The NARS is funded through the Treasury and its total allocation for research exceeds Rs. 80-85 million per year. However, the University staff gets very little funds from the University for research. For instance, the Faculty of Agriculture at the University of Peradeniya with a total staff strenth of over 


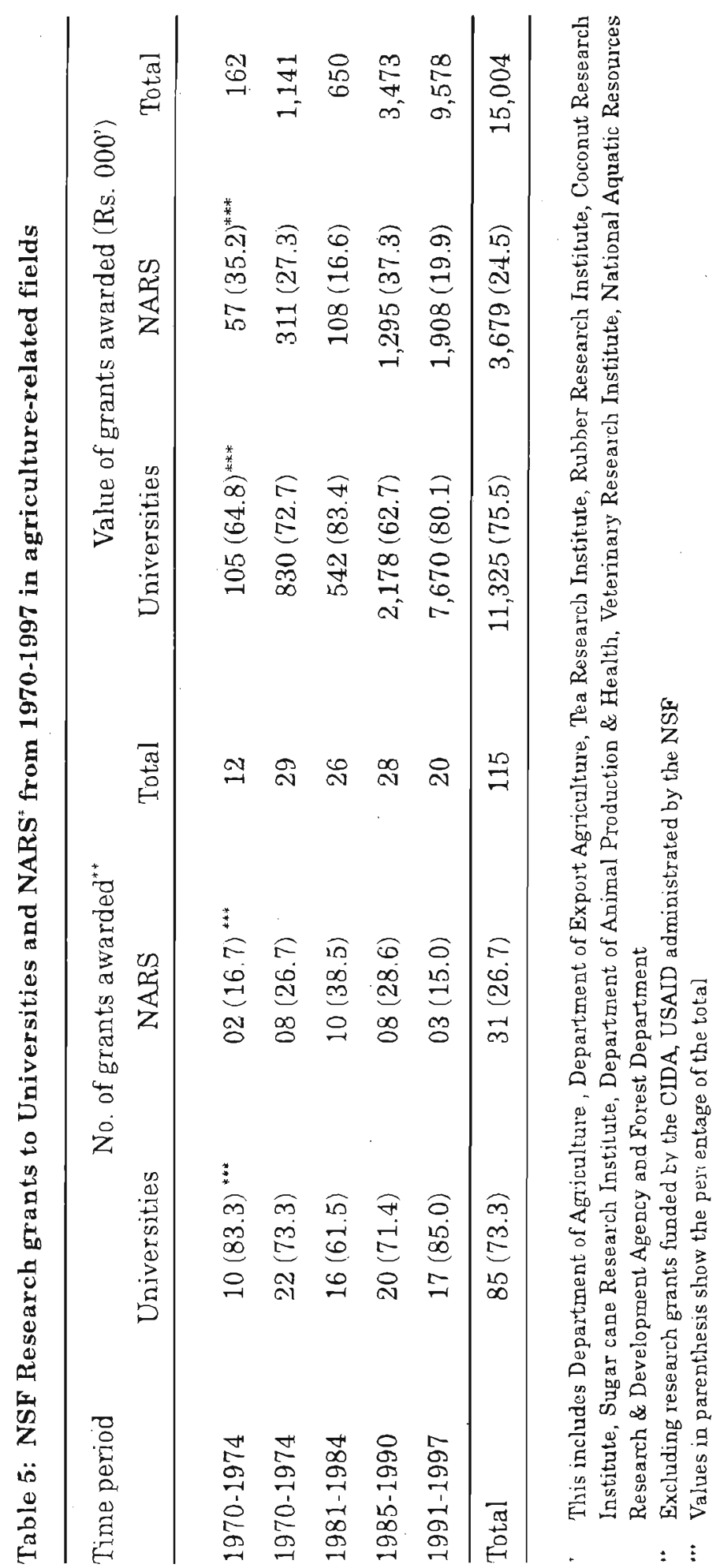


100 receives about $R$ s. 500,000 annually for staff research, and the Faculty of Agriculture at the University of Ruhuna with about 30 staff members gets about Rs. 250,000 per year. This amounts to only about Rs. 5,000-8,000 per head per year which is hardly adequate to do any useful research. Thus NSF has been a very important source of funding for research for the University staff. These grants, besides addressing issues in agriculture, have greatly helped to enhance the research capabilities, training including post-graduate studies of the University staff and to imporve infrastructure/ laboratory ficilities in the Faculties of Agriculture in the country.

Table 6: Relative contributions of the NSF and CARP to funding agricultural research from 1990-1998

\begin{tabular}{lccccc}
\hline & \multicolumn{2}{c}{ NSF Funding } & \multicolumn{2}{c}{ CARP Funding } & Tota] \\
Year & $($ Rs. $)$ & $(\%)$ & $($ Rs. $)$ & $(\%)$ & $($ Rs. $)$ \\
\hline 1990 & 559,380 & 3.7 & $14,605,567$ & 96.0 & $15,164,947$ \\
1991 & 309,660 & 0.9 & $35,512,149$ & 99.1 & $35,821,809$ \\
1992 & 556,049 & 1.8 & $30,541,578$ & 98.2 & $31,097,627$ \\
1993 & - & - & $16,793,260$ & 100.0 & $16,793,260$ \\
1994 & - & - & $24,746,865$ & 100.0 & $24,746,865$ \\
1995 & $1,971,000$ & 15.9 & $10,440,296$ & 84.1 & $12,411,296$ \\
1996 & $1,367,000$ & 10.0 & $12,341,321$ & 99.0 & $13,708,321$ \\
1997 & $5,108,550$ & 29.0 & $12,441,400$ & 70.9 & $17,549,950$ \\
1998 & $1,522,118$ & 7.0 & $20,771,670$ & 93.2 & $22,293,788$ \\
\hline Total & $11,393,757$ & $6.0^{*}$ & $178,194,106$ & $94.0^{*}$ & $189,587,863$ \\
\hline
\end{tabular}

'average

\section{Support for agricultural research from sources other than NSF}

In addition to the NSF, CARP and the other foreign institutions have also made a significant contribution in supporting agricultural research in the country. Until 1987, the NSF was the only national institution that provided funds for agriculture research. With the establishment of CARP in 1987, it has provided a substantial amount of funds for need-based and problem-focused agricultural research in the country. Though the research funding of the NSF has mainly gone to the Faculties of Agriculture, the CARP funding has been mainly in the NARS. Of the total research funding by CARP from 1990-98, over $80 \%$ has been in the NARS whereas the Faculties of Agriculture have received less than 20\%. 


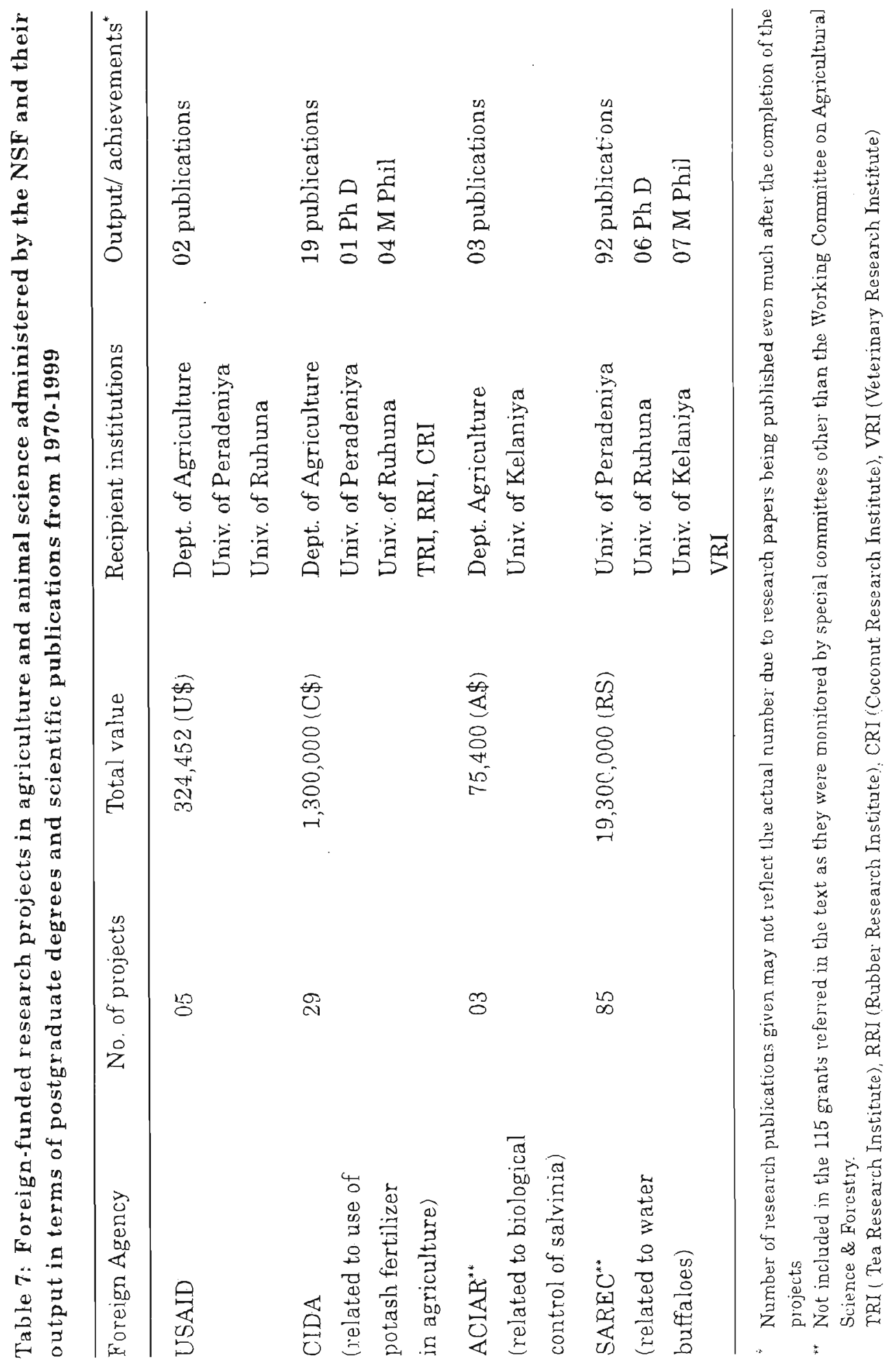


Agricultural Science is only one of the fifteen or more fields receiving research funds from the NSF. Funding of agricultural research by the NSF has varied from 1.5 to $35 \%$ of the total funds disbursed during the period of 1982 to 1999 (Table 2). On the other hand, CARP is funding for research only in the agriculture-related fields. Thus, the total value of research grants provided for agriculture during the period of 1990 - 1998 by the NSF has been Rs.11, 393,757.00 as against Rs. $178,194,106.00$ by CARP (Table 6).

Scientists, especially in the Universities/Faculties of Agriculture have been successful in attracting a considerable amount of research funds from foreign sources such as PSTC/USAID, BOSTID/NAS, IDRC, NORAD, CIDA, SIDA, IFS of Sweden, SAREC etc. Information on the total quantum of funds so received is not available, but it has undoubtedly been a significant source of funding for agriculture research in the country. Though the number of grants thus received may not be high, the average value of such grants is much higher than that provided by the NSF (Table 7).

\section{Benefits and achievements of NSF-funded research projects in agriculture and animal science}

From the foregoing, it was evident that the NSF has funded a total of 115 grants at a cost of Rs. $15,981,470$ during the period of 1970 to 1997 . Of these grants less than $6 \%$ (both in terms of number and value) has been in the field of animal husbandry, thus most of the projects have been related to agricultural crops, which mainly included fruit crops, cereals, plantation crops, export agricultural crops, and oil crops. Of the 115 grants awarded, all have been completed except 5 which have been withdrawn, or terminated due to reasons such as unsatisfactory progress, technical limitations etc.

The success and achievements of a given grant depends on a multitude of factors. Given the number of grants awarded by the NSF, the nature of issues and problems addressed, the commodity crop types involved, the large variations in the amount and value of the grants awarded and the varying circumstances under which they have been carried out, it is not only difficult, but also not fair and sensible to categorize them in terms of success or the impact they have made. But on the whole, the grants have been well executed, addressing important research issues in agriculture.

However, it should be mentioned that the ACIAR (Australian Centre for International Agricultural Research) project on "Biological control of Salvinia" administered by the NSF has been one of the most successful projects and the findings thereof have led to the control of. Salvinia in water bodies, canals etc., yielding substantial economic and environmental benefits. In recognition of the noteworthy contribution made by the NSF in supporting this environmentally 
important research project and thereby helping resolve some major environmental issues in the country, the NSF received the "Soba Cineru" award from the Sri Lanka Environmental Journalist Forum (SLEJF) in 1998.

The NSF-funded projects have also contributed to the advancement and dissemination of knowledge, improvement of laboratory/analytical facilities of the recipient institutions, human resource development/postgraduate training in the country etc. (Table 8). For instance, of the total value of the grants awarded by the NSF during the pexiod of $1970-97$, about $21 \%$ has been on equipment, thereby contributing significantly to the enhancement of laboratory facilities of recipient institutions. The progress review seminars on ongoing research grants organized by the NSF every year train the researchers in making presentations of their work at public gatherings and sharing their experience with others. They get an opportunity to publisize and disseminate their findings at exhibitions participated by the NSF, by way of models, posters, leaflets etc. It should be emphasized that these grants have also contributed in no small measure to promoting scientific thinking and intellectual activity and establishing professional contacts among the agricultural scientists in the country. The NSF has also established a merit award scheme in 1986 in order to appreciate and recognize the outstanding research contributions by the scientists, which will motivate the researchers to achieve excellence. Under this scheme, two merit awards have been given in 1986 and $1991 \mathrm{in}$ the field of Agriculture.

In addition to the postgraduate training provided under the NSF-funded research projects, the contribution by the NSF in terms of technical training has also been noteworthy. For instance, under the NSF-funded research projects in agriculture and animal science, about 50 technical and research personnel have been given necessary technical training to date and nearly 100 have been trained under foreign-funded research projects administered by the NSF. Besides, their participation in research programmes has helped them acquire new knowledge and skills relevant to their career development and as a matter of fact, some officers have secured better employment consequent to the technical training so received.

The international contacts fund established by the NSF in 1984 with generous funding from Swedish International Development Agency (SIDA) has provided travel support to many scientists to make presentations at international symposia, seminars, workshops, conferences etc. and for short-term overseas training. Under the scheme, the NSF has provided travel grants to 65 agricultural scientists during the period of 1995 to 1999. This scheme, besides enabling local scientists to attend international meetings and training programmes, has helped them to keep abreast of the latest developments and research trends in their respective fields and to establish international contacts. Thus this travel grant scheme has indirectly contributed towards agricultural research through motivating the scientists and enhancing their research capabilities and professional competence. 
It is evident from Table 7 and 8 that the number of post-graduates and the publications produced by the foreign-funded projects had far exceeded that produced by the NSF-funded research projects. The higher output from the foreign-funded projects may be attributed to relatively higher allowance paid to research assistants, provision of more funds for equipment and consumables, longer project duration, foreign collaboration, frequent and rigorous monitoring etc.

Table 8: Some basic information on the grants awarded by the NSF during 1970-1997

Item

Number of grants awarded

Total funds allocated (Rs. x 10 $)$

Total expenditure (Rs. x 10 $)$

Expenditure on equipment (Rs. $\times 10^{3}$ )

Percentage of expenditure on equipment as a percentage of the

total value of the grants awarded

No. of Research Assistants appointed

Master degrees completed

Ph.D degrees completed

Postgraduate degrees produced as a percentage of the total

number of grants awarded

Publications in international journals

Publications in the local journals

Other scientific communications
Amount/Number

\section{5}

15,981

11,304

2,410

21

42

12

01

09

24

26

In conclusion, the authors wish to make the following recommendations in order to improve the effectiveness of the NSF research grants scheme, so that the outcome of the projects will have a significant impact to the national development.

(1) Indicate as far as possible, the priority crons and livestock and priority research areas as well as the major issues that need to be addressed when the NSF research grants scheme is advertised. Thus, the research proposals will mainly focus on high priority research concerns, thereby helping the NSF to disburse funds more meaningfully.

(2) Promote inter-disciplinary and inter-institutional research. Of the grants awarded, the vast majority did not involve a multi-disciplinary approach. When multi-disciplinary research is done the value of the grants will be naturally higher, so that the number of grants that can be awarded may 
be less, but the impact would be grater. The Working Committee on Agricultural Science of the NSF may even play a role of facilitator in identifying relevant multi-disciplinary research and relevant institutes, and encourage them to apply for research grants.

(3) Monitor the progress of the grants awarded through periodic visits to the grantees by the members of the Working Committee. This would enable the Committee not only to better assess the progress of the grantees, but also to ascertain the difficulties and problems faced by them, enabling necessary timely intervention.

(4) Encourage grantees to publish their findings. Though the NSF has funded about 115 agricultural research projects from 1970 to 1997, according to the available records, they have produced only 09 international papers, 24 papers in local journals and about 25 short communications, amounting to nearly a total of 50 . This is grossly inadequate. Hence the grantees should be encouraged to publish the results and the NSF journal may give special consideration to research papers resulting from the NSF- funded research projects.

\section{Acknowledgement}

The authors thank Kevin Hall for his help given in retrieving relevant information from the NSF data base on research grants and Tushara Vitiyala for her kind assistance in preparing part of the tables in this paper.

\section{References}

1. Anon. (1998). Economic progress of independent Sri Lanka - 1948-1998 Central Bank of Sri Lanka. pp. 295

2. Gunasena H.P.M. \& Marambe B. (1998). University research-agriculture interface. A paper presented at a seminar on "University Research". 12-13 December, Rajarata University, Mihintale, Sri Lanka.

3. Senanayake Y.D.A. (1990). Overview of the organization and structure of national agricultural research systems in Asia. ISNAR Working Paper No. 32 , ISNAR, the Netherlands.

4. Anon. (1987a). The Council for Agricultural Research Policy, Souvenir Publication. Publication by the Ministry of Agricultural Development and Research, Colombo 03. pp. 72 
5. Anon. (1987b). Staff appraisal report on Sri Lanka agricultural research project, 04 March. World Bank Document.

6. Mahindapala R. (1981). Fifty years of coconut research, Tropical Agriculturist, $137,89-95$

7. Anon. (1984). Proceedings of the international rubber conference " 75 years of rubber research in Sri Lanka". 17-19 September, Colombo published by the Rubber Research Institute, Agalawatte, Vol. 1 part I

8. NSC, NARESA, NSF Annual Reports (1970-1998)

9. NSF data base on research grants (1970-1999) 